Original Research Article

\title{
Pattern of antimicrobial usage for prophylaxis of surgical site infection in a tertiary care hospital of Western Uttar Pradesh
}

\author{
Parul Kesar $^{1 *}$, Surabhi Gupta ${ }^{1}$, H. L. Bhalla1, Anita Panday ${ }^{2}$
}

\begin{abstract}
${ }^{1}$ Department of Pharmacology,
${ }^{2}$ Department of Microbiology,

Subharti Medical College,

Meerut, Uttar Pradesh, India
\end{abstract}

Received: 27 December 2018

Accepted: 29 January 2019

*Correspondence to:

Dr. Parul Kesar,

Email: drparulkesar07@

gmail.com

Copyright: (C) the author(s), publisher and licensee Medip Academy. This is an openaccess article distributed under the terms of the Creative Commons Attribution NonCommercial License, which permits unrestricted noncommercial use, distribution, and reproduction in any medium, provided the original work is properly cited.

\begin{abstract}
Background: The practice of giving antibiotic prophylaxis has resulted in the reduction of surgical site infections (SSI), thus reducing cost, morbidity, and mortality. Common nosocomial infections in surgical patients include SSIs, urinary tract infections (UTIs), pneumonias and blood stream infections (BSIs). The present study was, therefore, designed to analyze the efficacy of antimicrobials used for prophylaxis during surgery in a tertiary care hospital in India.

Methods: Total 100 patients were enrolled. Name, timing, route, dose of antimicrobials given were recorded. All the relevant data was taken from the patient's medication charts and medical records. Chi-square test and t-test were applied.

Results: The optimal time of giving antimicrobial prophylaxis in present study was 1 hour before the surgery. A total of 8 different antimicrobials were prescribed to 100 patients, out of which most commonly prescribed were cephalosporin i.e. $82 \%$. Majority of SSI $(57.12 \%)$ occurred when the duration of surgical antimicrobial prophylaxis (SAP) was for $\geq 2$ hours ( $\mathrm{p}$ value <0.05). Common organisms seen in SSI were E. coli, S. aureus, Pseudomonas and Kleibsella species. The hospital stay of patients with SSI was more as compared to patients without SSI in present study ( $\mathrm{p}$ value $<0.05$ ).

Conclusions: It has been observed that inappropriate selection and timing of giving SAP play an important role in developing SSI, which can be adequately controlled by adopting SAP guidelines, good infection control practices and risk factor analysis.
\end{abstract}

Keywords: Antimicrobials, Surgical antimicrobial prophylaxis, Surgical site infection

\section{INTRODUCTION}

The burden of infectious diseases in India is one of the highest in the world. ${ }^{1}$ Antibiotics are among the most frequently prescribed drugs worldwide. ${ }^{2,3}$ The concern of clinicians regarding inappropriate antibiotic use is a serious matter because it not only enhances the risk of emergence of multidrug-resistant bacteria but also imposes a financial burden on patients from lower socioeconomic status.

Antimicrobial prophylaxis, a very brief course of antibiotics initiated just before the start of surgical procedures, recommended to reduce postoperative infection. ${ }^{4}$ The practice of giving antibiotic prophylaxis has resulted in the reduction of surgical site infections, thus reducing cost, morbidity, and mortality. ${ }^{5,6}$ But inappropriate prophylaxis by unnecessary use of broadspectrum agents and continuation of therapy beyond the recommended time period increases the risk of adverse effects and promote the emergence of resistant organisms.

Common nosocomial infections in surgical patients include surgical site infections (SSIs), urinary tract infections (UTIs), pneumonias and blood stream infections (BSIs). 
The present study was, therefore, designed to analyze the efficacy of antimicrobials used for prophylaxis during surgery in a tertiary care hospital in India.

\section{METHODS}

This prospective, observational study was carried out in a tertiary care hospital - Chhatrapati Shivaji Subharti Hospital, Subharti Medical College, Meerut, India after receiving approval from the Institutional Ethics Committee (IEC). The study was carried out in male and female surgical, orthopedics, obstetrics and gynecology wards of CSSH, Meerut. Adult patients who underwent surgery were included in the study. Total 100 patients were enrolled. Name and timing of antimicrobials given were recorded. Surgical site assessment was done by clinical symptoms, examination and microbiological evaluation if needed. Compliance with antimicrobial guidelines was assessed and deviation if any with reasons was recorded. Duration of stay and time of discharge after surgery or any other intervention was recorded. Any secondary / nosocomial infection (mouth, respiratory, urinary, GIT, skin or others) was recorded. All the relevant data was taken from the patient's medication charts and medical records. Details recorded included patient's demographic data, antibiotic allergy, type of surgery, wound class (clean, clean-contaminated or contaminated), duration of operation, and parameter of antibiotic prophylaxis (antibiotic choice, route, dose, timing and duration of prophylaxis).

\section{Inclusion criteria}

Adult patients who underwent surgical procedures in Department of Surgery, Orthopedics and Obstetrics and Gynaecology were included.

\section{Exclusion criteria}

- $\quad$ Patients aged less than 14yrs

- Patients who were not willing to give consent.

\section{Statistical analysis}

Data entry was made from the case record form into the Microsoft Excel program. Chi-square test and T-test are applied. SPSS was used for statistical analysis.

\section{RESULTS}

Of all the 100 patients enrolled, $47 \%$ were males and $53 \%$ were females (Table 1), 35 patients were enrolled from department of surgery, 29 from orthopaedics and 36 from obstetrics and gynaecology (Table 2). Out of total 100 patients, $87 \%$ patients showed favourable results while $13 \%$ patients showed unfavourable results i.e. presence of post-surgery infection (Table 3). A total of 13 different antimicrobial combinations were prescribed to 100 patients. Highly prescribed antimicrobial was Ceftriaxone i.e. prescribed to $62 \%$ patients while, amikacin (10\%), cefuroxime $(8 \%)$, cefuroxime-amikacin $1 \%$, cefotaximesulbactum $(1 \%)$, cefoperazone- sulbactum + gentamicin $(1 \%)$, ceftriaxone- sulbactum (3\%), cefoperazonesulbactum + amikacin (1\%), cefotaxime- sulbactum+ amikacin (1\%), amoxicillin-clavulinic acid (4\%), ampicillin (3\%) and cefoperazone (3\%), ampicillinclavulinic acid (4\%) (Table 4).

Table 1: Gender distribution.

\begin{tabular}{|lll|}
\hline Gender & No. of patients & Percentage $(\%)$ \\
\hline Male & 47 & 47.0 \\
\hline Female & 53 & 53.0 \\
\hline Others & Nil & Nil \\
\hline Total & 100 & 100.0 \\
\hline
\end{tabular}

Table 2: Distribution of patients based on surgical department.

\begin{tabular}{|lll|}
\hline Department & No. of patients & Percentage \% \\
\hline Surgery ward & 35 & 35 \\
\hline Orthopaedic ward & 29 & 29 \\
\hline $\begin{array}{l}\text { Gynaecology and } \\
\text { Obstetric ward }\end{array}$ & 36 & 36 \\
\hline Total & 100 & 100 \\
\hline
\end{tabular}

Table 3: Outcome of surgical antimicrobial prophylaxis.

\begin{tabular}{|ll|}
\hline Outcome & No. of patients \\
\hline Favourable & 87 \\
\hline Not favourable & 13 \\
\hline
\end{tabular}

Table 4 Details of antimicrobials prescribed for surgical prophylaxis with ATC classification.

\begin{tabular}{|l|l|l|}
\hline Antimicrobial agent & $\begin{array}{l}\text { No. of } \\
\text { patients } \\
\text { prescribed } \\
(\%)\end{array}$ & $\begin{array}{l}\text { ATC } \\
\text { classification }\end{array}$ \\
\hline Ceftriaxone only & 62 & J01DD \\
\hline Ceftriaxone- sulbactum & 3 & J01DD \\
\hline Ceftriaxone+ Amikacin & 5 & J01DD \\
\hline Cefuroxime & 8 & J01DC \\
\hline Cefuroxime+Amikacin & 1 & J01DC \\
\hline Cefotaxime- sulbactum & 1 & J01DD \\
\hline $\begin{array}{l}\text { Cefoperazone- } \\
\text { sulbactum+ gentamicin }\end{array}$ & 1 & J01DD \\
\hline $\begin{array}{l}\text { Cefoperazone- } \\
\text { sulbactum + amikacin }\end{array}$ & 1 & J01DD \\
\hline $\begin{array}{l}\text { Cefotaxime- } \\
\text { sulbactum+ amikacin }\end{array}$ & 1 & J01DD \\
\hline Amikacin & 10 & J01G \\
\hline $\begin{array}{l}\text { Ampicillin-clavulinic } \\
\text { acid }\end{array}$ & 4 & J01FA \\
\hline Ampicillin & 3 & J01FA \\
\hline Total & 100 & J01 \\
\hline
\end{tabular}


Table 5: Incidence of SSI according to timing of antimicrobial prophylaxis.

\begin{tabular}{|llll|}
\hline Timing & $\begin{array}{l}\text { Total } \\
\text { patients }\end{array}$ & $\begin{array}{l}\text { SSI not } \\
\text { present }\end{array}$ & $\begin{array}{l}\text { SSI present } \\
\text { (percentage) }\end{array}$ \\
\hline$<2$ hours & 93 & $85(91 \%)$ & $08(8.6 \%)$ \\
\hline$>2$ hours & 07 & $03(42.8 \%)$ & $04(57.12 \%) *$ \\
\hline *P value $<0.05$ & & & \\
\hline
\end{tabular}

Table 6: Organisms seen after culture sensitivity.

\begin{tabular}{|ll|l|}
\hline $\begin{array}{l}\text { Organisms seen after } \\
\text { culture sensitivity }\end{array}$ & $\begin{array}{l}\text { Number of } \\
\text { patients }\end{array}$ & $\begin{array}{l}\text { Percentage } \\
(\%)\end{array}$ \\
\hline E.coli & 6 & 46.15 \\
\hline Pseudomonas species & 4 & 30.8 \\
\hline Staphylococcus aureus & 2 & 15.4 \\
\hline Kleibsella species & 1 & 7.8 \\
\hline
\end{tabular}

Total of 93 patients received Surgical Antimicrobial Prophylaxis (SAP) <2hours before surgery and out of 93, 8 patients suffered from Surgical Site Infection (SSI) i.e. $8.6 \%$. 07 patients received SAP $>2$ hours before surgery and out of 07, 04 patients suffered from SSI i.e.57.14\% (p value $<0.05$ ) (Table 5).

Most common organism encountered at surgical site were E. coli (46.15\%), followed by Pseudomonas species $(30.8 \%)$ S. aureus $(15.4 \%)$ and Kleibsella species $(7.8 \%)$ (Table 6). The hospital stay of patients with SSI was $4.5 \pm 2.12$ days and patients without SSI was $2.5 \pm 2.23$ days with a $\mathrm{p}$ value of 0.00017 which is highly significant (Table 7).

Table 7: Hospital stay (days) of patients with/without SSI.

\begin{tabular}{|llll|}
\hline Group & $\begin{array}{l}\text { Hospital stays } \\
\text { (days) }\end{array}$ & P value & Significance \\
\hline With SSI & $4.5 \pm 2.12$ & $0.00017 *$ & $\begin{array}{l}\text { Highly } \\
\text { significant }\end{array}$ \\
\hline $\begin{array}{l}\text { Without } \\
\text { SSI }\end{array}$ & $2.5 \pm 2.23$ & 2. & \\
\hline
\end{tabular}

\section{DISCUSSION}

With the advent of newer costly antibiotics, cost of treatment has increased many folds. In additions, resistant pathogens, nosocomial infections and cross infections further increase the financial burden on patient.

In our study, out of 100 patients, 35 patients were enrolled from department of surgery, 29 from orthopaedics and 36 from obstetrics and gynaecology. $47 \%$ were males and $53 \%$ were females with mean age of $(43.06 \pm 17.40)$ and $(39.85 \pm 15.66)$ years respectively .The reason for $53 \%$ females could be due to inclusion of female department exclusively i.e. department of gynaecology and obstetrics.

The optimal time of giving antimicrobial prophylaxis in our study was 1 hour before the surgery i.e. in $93 \%$ patients; antimicrobials were given with in 1 hour before surgery, which is in accordance to the ICMR treatment guidelines which recommends that antibiotics should be administered before an incision is made to ensure that antimicrobial levels in the tissue are adequate and maintained for the duration of the procedure and prophylaxis should be started preoperatively in most circumstances, ideally within 30-60 minutes before incision. $^{7}$

A previous study also recommended administration of the first dose of the antimicrobial beginning within 60 minutes before surgical incision. ${ }^{8}$

Our data suggests that majority of SSI (57. 12\%) occurred when the duration of SAP was for $\geq 2$ hours ( $p$ value $<0.05$ ). These findings are similar to findings of previous study which reported that compared with antibiotic administration within 60 minutes prior to incision, higher SSI rates were observed for timing more than 60 minutes prior to incision. ${ }^{9}$

It has been observed that duration of surgery also influences wound infection and procedures that take more than two hours are associated with higher infection rates. Longer exposure of tissues to theatre environment, hypothermia and requirement of blood transfusion, all of them are potential risk factors for SSI. Present study reveals a clear-cut increased number of SSI cases i.e. $26 \%$ cases, where surgery has been prolonged $\geq 2$ hours. Studies conducted on SSI in Aurangabad, Mumbai, Hyderabad, have reported a similar observation. In fact, this correlation has been established since 1964 by the Public health laboratory services (PHLS) in England and Wales. ${ }^{10-13}$

In present study authors found that total of 8 different antimicrobials were prescribed to100 patients. Out of which most commonly prescribed antimicrobial were cephalosporins i.e. $82 \%$ and among them, third generation cephalosporins were most commonly used. According to SIGN and ASHP guidelines, cefazolin (first generation cephalosporin) should be the drug of choice for prophylaxis of surgical site infection but resistance to $1^{\text {st }}$ and $2^{\text {nd }}$ generation cephalosporin is very common in our setting because these antibiotics are used for common infections. ${ }^{14}$ Hence, for this reason third generation cephalosporins were preferred in our study. Present study findings are similar to findings of a previous study where they reported that the most frequently prescribed classes of antibiotics were cephalosporins (42\%) followed by penicillins $(34 \%)$ and out of cephalosporin group, $10 \%$ received ceftriaxone prior to their surgery. ${ }^{15}$

For surgical prophylaxis it is important to select an antibiotic with narrowest antibacterial spectrum to reduce the emergence of resistance and also because broad spectrum antibiotics may be required later if patient develops serious sepsis. Therefore, it is recommended that the use of third generation cephalosporins such as 
ceftriaxone and cefotaxime be avoided in surgical prophylaxis. $^{16}$

Most common organism seen in surgical site infection was E. coli, Staphylococcus aureus, Pseudomonas and Kleibsella species. These findings are similar to the findings of a study which reported that E. coli was the commonest pathogen, followed by Pseudomonas aeruginosa and Staphylococcus aureus while some studies reported that $S$. aureus is the most common organism predominantly isolated from SSI. ${ }^{17-19}$ The possible reason for this difference is that there is different pattern of organisms in different hospital setups and lesser number of abdominal and perineal operations in these studies were included, compared to present study.

The hospital stay of patients with SSI was more as compared to patients without SSI in our study ( $p$ value of 0.00017 ). A previous study reported a mean duration of 6.4 days of antibiotic use in a study of Taiwanese patients. ${ }^{20}$ Even though evidence from literature fails to support prolonged administration of antimicrobial agents in the hospitals, usage beyond 24 hours is common. ${ }^{21}$ Longer courses of antibiotics are falsely believed to be a good preventive measure against SSI.

\section{ACKNOWLEDGEMENTS}

Authors would like to thank to Dr. P. P Khosla, Dr. Shashi Prateek, Dr. Y.P Monga and Dr. Arunim Swaroop, Subharti Medical College Meerut, for their invaluable help and expert guidance in the execution of this work.

Funding: No funding sources

Conflict of interest: None declared

Ethical approval: The study was approved by the Institutional Ethics Committee

\section{REFERENCES}

1. Ahmad A, Parimalakrishnan S, Mohanta GP, Patel I, Manna PK. A study on utilization pattern of higher generation antibiotics among patients visiting community pharmacies in Chidambaram, Tamil Nadu at South India. Int J Pharm. 2012;2(3):466-71.

2. Ozkurt Z, Erol S, Kadanali A, Ertek M, Ozden K, Tasyaran MA. Changes in antibiotic use, cost and consumption after an antibiotic restriction policy applied by infectious disease specialists. Japanese $\mathrm{J}$ Infect Dis. 2005 Dec 1;58(6):338.

3. Fadare JO, Tamuno I. Antibiotic self-medication among university medical undergraduates in Northern Nigeria. J Public Health Epidemiol. 2011 May 31;3(5):217-20.

4. Waddell TK, Rotstein OD. Antimicrobial prophylaxis in surgery. Committee on Antimicrobial Agents, Canadian Infectious Disease Society. Canadian Med Assoc J. 1994 Oct 1;151(7):925.
5. Geroulanos S, Marathias K, Kriaras J, Kadas B. Cephalosporins in surgical prophylaxis. J Chemotherapy. 2001 Jan 1;13(sup4):23-6.

6. McGowan Jr JE. Cost and benefit of perioperative antimicrobial prophylaxis: methods for economic analysis. Rev Infect Dis. 1991 Sep 1;13(Supplement_10):S879-89.

7. Antimicrobial guidelines for prophylaxis and treatment of surgical site infections. Treatment Guidelines for Antimicrobial Use in Common Syndromes. Indian Council of Medical Research Department of Health Research New Delhi, India $2017 . \quad$ Available at: https://www.icmr.nic.in/sites/default/files/guidelines/t reatment_guidelines_for_antimicrobial.pdf.

8. Bratzler DW, Houck PM, Richards C, Steele L, Dellinger EP, Fry DE, et al. Use of antimicrobial prophylaxis for major surgery: baseline results from the National Surgical Infection Prevention Project. Arch Surg. 2005 Feb 1;140(2):174-82.

9. Hawn MT, Richman JS, Vick CC, Deierhoi RJ, Graham LA, Henderson WG, et al. Timing of surgical antibiotic prophylaxis and the risk of surgical site infection JAMA Surg. 2013 Jul;148(7):649-57.

10. Anvikar AR, Deshmukh AB, Karyakarte RP, Damle AS, Patwardhan NS, Malik AK, et al. A one year prospective study of 3280 surgical wounds. Indian J Med Microbiol. 1999;17(3):129-32.

11. Lilani SP, Jangale N, Chowdhary A, Daver GB. Surgical site infection in clean and clean-contaminated cases. Indian J Med Microbiol. 2005;23(4):249-52.

12. Rao AS, Harsha M. Postoperative wound infections. J Indian Med Asso. 1975;64(4):90-3.

13. Berard F, Gandon J. Factors influencing the incidence of wound infection. Ann Surg. 1964;160:32-81.

14. Clinical Practice Guidelines for Antimicrobial Prophylaxis in Surgery ASHP Therapeutic Guidelines. Available at: https://www.ashp.org//media/assets/policy-guidelines/docs/therapeuticguidelines/therapeutic-guidelines-antimicrobialprophylaxis surgery.ashx?la=en\&hash=A15B4714417A51A03E5 BDCAC150B94EAF899D49B.

15. Rehan HS, Kakkar AK, Goel S. Pattern of surgical antibiotic prophylaxis in a tertiary care teaching hospital in India. Int J Infection Control. 2010;6(2).

16. Munckhof W. Antibiotics for surgical prophylaxis. Australian prescriber. 2005 Apr 1;28(2):38-40.

17. Khairy GA, Kambal AM, Al-Dohayan AA, Al-Shehri MY, Zubaidi AM, Al-Naami MY, et al. Surgical Site Infection in a Teaching Hospital: A Prospective Study. J Taibah University Med Sci 2011; 6(2):114-20.

18. Shinde A, Kulkarni S. Study of organisms causing surgical site infections and their antimicrobial susceptibility pattern in rural teaching hospital. MIMER Med J. 2017;1(2):9-12.

19. Mundhada AS, Tenpe S. A study of organisms causing surgical site infections and their antimicrobial susceptibility in a tertiary care Government Hospital. Indian J Pathol Microbiol. 2015 Apr 1;58(2):195. 
20. Chen YS, Liu YC, Kunin CM, Huang JK, Tsai CC Use of prophylactic antibiotics in surgery at a medical center in southern Taiwan. J Formosan Med Assoc. 2002 Nov 1;101(11):741-8.

21. Bratzler DW, Houck PM, Richards C, Steele L, Dellinger EP, Fry DE, et al. Use of antimicrobial prophylaxis for major surgery: baseline results from the National Surgical Infection Prevention Project. Arch Surg. 2005 Feb 1;140(2):174-82.
Cite this article as: Kesar P, Gupta S, Bhalla HL, Panday A. Pattern of antimicrobial usage for prophylaxis of surgical site infection in a tertiary care hospital of Western Uttar Pradesh. Int J Basic Clin Pharmacol 2019;8:534-8. 